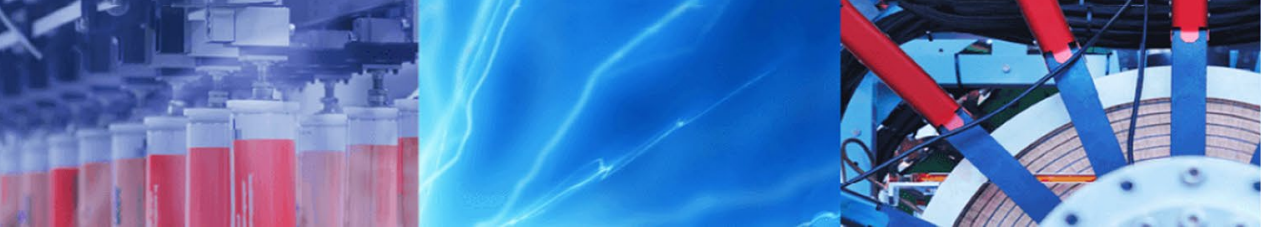

Research Article

\title{
Cold atmospheric plasma surface nanoengineered carboxymethyl cellulose hydrogels as oral ibuprofen carriers
}

\author{
Smruti Prava Das ${ }^{1} \cdot$ Ganeswar Dalei $^{1} \cdot$ Satyabrata Sahoo ${ }^{1} \cdot$ Subhraseema Das $^{1}$
}

(c) Springer Nature Switzerland AG 2019

\begin{abstract}
Smart hydrogels comprising polyvinyl alcohol and carboxymethyl cellulose have been fabricated using a green crosslinker tetraethyl orthosilicate. The hydrogels were subjected to cold atmospheric plasma-treatment using pure $\mathrm{Ar}$, pure $\mathrm{NH}_{3}$ and a mixture of the two. Enhanced surface wettability was witnessed post-plasma treatment; irrespective of the plasma gas employed. An insignificant surface ageing of the hydrogels was marked upon exposure to air for 10 days. AFM analyses revealed the surface topographical changes at the nano level while the bulk attributes remained unaffected. The hydrogels displayed smart swelling features. The release of ibuprofen from the hydrogels in simulated gastric and intestinal fluids affirmed their potential towards oral colon-targeted drug delivery. The preliminary kinetics of drug release indicated the anomalous nature of drug transport mechanism. More so, drug release from plasma-treated hydrogels were predominantly governed by diffusion process rather than polymer chain relaxational process. The hydrogels demonstrated good biodegradability and could be efficaciously utilized as potential oral drug delivery candidates.
\end{abstract}

Keywords Carboxymethyl cellulose PVA DBD plasma - Oral ibuprofen delivery

\section{Introduction}

Hydrogels, as perpetual biomaterials, have grown exponentially in recent years owing to their uncanny resemblance to living tissues. They have flourished as reliable candidates for drug delivery and demonstrated terrific potential in tissue engineering [1-6]. Over the last decade; considerable efforts have been made to develop more efficient hydrogels for applications in biomedical fields. Most of these endeavours have aimed at modifying the surface properties of the hydrogels in order to accomplish their clinical potential. Tailoring the surface generally imparts certain functionalities (including bioactive groups) and alters surface properties such as wettability, free energy and topography that are crucial to enhance the bio-responsivity of the polymer [7-10].

Of the various methods implemented to tailor the surface properties of hydrogels; the use of cold atmospheric plasma has gained thrust lately. Dielectric barrier discharge (DBD) plasma is one of the promising methods to improve surface wetting and adhesion properties of a polymeric biomaterial. It is a solvent-free single step process that enables the introduction of different functional groups in a short time span [11-15]. Compared to other plasma methods; DBD plasma treatment allows for continuous in-line processing and can be operated at atmospheric pressure [16]. These factors lead to low operational and maintenance costs $[10,16]$. Apart from being environmentally benign; DBD plasma modification is known to induce nano-/micro-topographies without affecting the bulk attributes of the biomaterial [15]. Thus, surface modification via DBD atmospheric plasma has blossomed into a versatile strategy for polymeric biomaterials.

Hydrogels comprising natural polysaccharides are much in demand owing to their high biocompatibility and biodegradability. In this context; cellulose, the most abundant

Smruti Prava Das, spdas@ravenshawuniversity.ac.in; $\bowtie$ Subhraseema Das, subhraseema@gmail.com| ${ }^{1}$ Plasma Research Laboratory, Department of Chemistry, Ravenshaw University, Cuttack, Odisha 753003, India.

SN Applied Sciences (2019) 1:1328 | https://doi.org/10.1007/s42452-019-1372-9

Received: 9 August 2019 / Accepted: 27 September 2019 / Published online: 4 October 2019 
natural resource on earth, is of great importance and finds unparallel applications in medicine [17-20]. However, the applicability of cellulose is largely impeded owing to its insolubility in a variety of solvents [21,22]. One of the simplest strategies to obviate this shortcoming has been by the synthesis of cellulose derivatives such as hydroxypropyl-cellulose or carboxymethyl-cellulose. Carboxymethylation, in general, is mostly chosen due to the technical simplicity of the process [23]. Carboxymethylation increases the hydrophilicity and solution clarity thereby improving the aqueous solubility of cellulose $[23,24]$. Additionally, pendant carboxylic acid groups that tend to attach to the cellulose backbone post-carboxymethylation render a $\mathrm{pH}$-sensitivity to the otherwise unresponsive pristine cellulose [25]. Carboxymethylated cellulose (CMC) has often been amalgamated with various polymers to cater to a wide array of biomedical applications [25-30]. One such polymer of eminence is polyvinyl alcohol (PVA) that has carved a niche for itself in pharmaceutical utilities. The versatility of PVA is paramount in the fabrication of a variety of architectures including films, microgels, microspheres, microbubbles and microcapsules $[31,32]$. Owing to its good film forming ability, long-term temperature and $\mathrm{pH}$ stability; PVA-based hydrogels find a greater call in biomedical research [33-36]. Several studies have reported the successful design of PVA/CMC hydrogels for potential applications in medicine [23, 37-42]. Literature also points towards the utilities of the aforesaid hydrogels in agriculture, dye removal and other industrial areas [43-52]. However, till date, no work has focussed on the surface engineering of PVA/CMC hydrogels by DBD plasma, their subsequent physicochemical properties and application as oral drug carriers.

In this research contribution, surface modification of PVA/CMC hydrogels have been performed in atmospheric pressure $\mathrm{Ar}, \mathrm{NH}_{3}$ and a mixture of $\mathrm{Ar}$ and $\mathrm{NH}_{3} \mathrm{DBD}$ plasmas. The hydrogels have been fabricated using tetraethyl orthosilicate (TEOS) as the crosslinker. TEOS has particularly been chosen because it is a green crosslinker and widely accepted in pharmaceutical formulations [53]. The influence of plasma treatment on the hydrogels have been investigated by contact angle, FTIR and AFM analyses. This study also explores the possible application of the hydrogels towards the oral delivery of the non-steroidal anti-inflammatory drug (NSAID), ibuprofen, to the colon. Further, the biodegradability of the hydrogels has been assessed by the soil burial test.

\section{Experimental}

\subsection{Materials}

PVA $\left(M_{w}=89,000-98,000 ; 99.0 \%\right.$ hydrolyzed), Cellulose (microcrystalline powder having particle size $20 \mu \mathrm{m}$ ),
Ibuprofen (IBF) and TEOS were procured from SigmaAldrich, India and used as received. Chloroacetic acid was procured from Merck India Ltd. and used as such. Deionized water from a Millipore Milli Q system was employed throughout. All other reagents used were of analytical grade purity.

\subsection{Synthesis of carboxymethyl cellulose (CMC)}

CMC was synthesized as per the reported method [54]. Briefly, cellulose $(3 \mathrm{~g})$ was dispersed in $100 \mathrm{~mL}$ of isopropanol and mechanically stirred at room temperature for 2 h. $80 \mathrm{~mL}$ of $60 \% \mathrm{NaOH}(\mathrm{w} / \mathrm{v}$ ) was added gradually over a period of $20 \mathrm{~min}$ and left under continuous stirring for $2 \mathrm{~h}$. Subsequently, $100 \mathrm{~mL}$ of chloroacetic acid $(60 \%$ $\mathrm{w} / \mathrm{v}$ ) was added to the reaction mixture; the temperature raised to $60^{\circ} \mathrm{C}$ and allowed to react for the next $6 \mathrm{~h}$. It was filtered, suspended in $150 \mathrm{~mL}$ of $80 \%$ methanol and neutralized with acetic acid. The final solid product (CMC), thus obtained, was thoroughly washed with methanol and dried at $60^{\circ} \mathrm{C}$.

\subsection{Synthesis of PVA/CMC hydrogels}

PVA solution (10 wt\%) was prepared by dissolving in water. Aqueous CMC solution (10 wt\%) was added to PVA solution to form a homogeneous solution. To the above solution mixture, TEOS $(2 \mathrm{~mL})$ was added dropwise and the reaction mixture was stirred for a brief period. The solution was then cast onto petri plates and dried in vacuo. The hydrogels were repeatedly washed with deionized water to remove the unreacted reagents and dried for further uses.

\subsection{DBD plasma treatment of hydrogels}

Surface modification of the hydrogels was performed in an atmospheric pressure DBD plasma reactor. A schematic of the DBD set-up is presented in Fig. 1. The DBD system consists of two parallel stainless-steel electrodes $(30 \mathrm{~cm} \times 30 \mathrm{~cm})$ and a $2 \mathrm{~mm}$-thick dielectric glass plate covering both the electrodes. The upper electrode is connected to a high voltage AC source $(0-30 \mathrm{kV}, 50 \mathrm{~Hz}$, Zeonics Systech, India), while the lower electrode is grounded. The hydrogel specimen was kept in-between the two electrodes and the plasma-generating gas was driven into the plasma chamber. The gas flowrate was monitored by a digital mass-flow controller (Sevenstar Electronics Co. Ltd., China). For pure Ar and pure ammonia; the gas flowrate was maintained at $0.5 \mathrm{Lpm}$ (Litre per minute). For the $\mathrm{Ar} /$ $\mathrm{NH}_{3}$ mixture; Ar flowrate was maintained at $0.5 \mathrm{Lpm}$ while it was kept constant at $0.125 \mathrm{Lpm}$ for $\mathrm{NH}_{3}$. 
Fig. 1 Schematic illustration of the DBD plasma reactor set-up

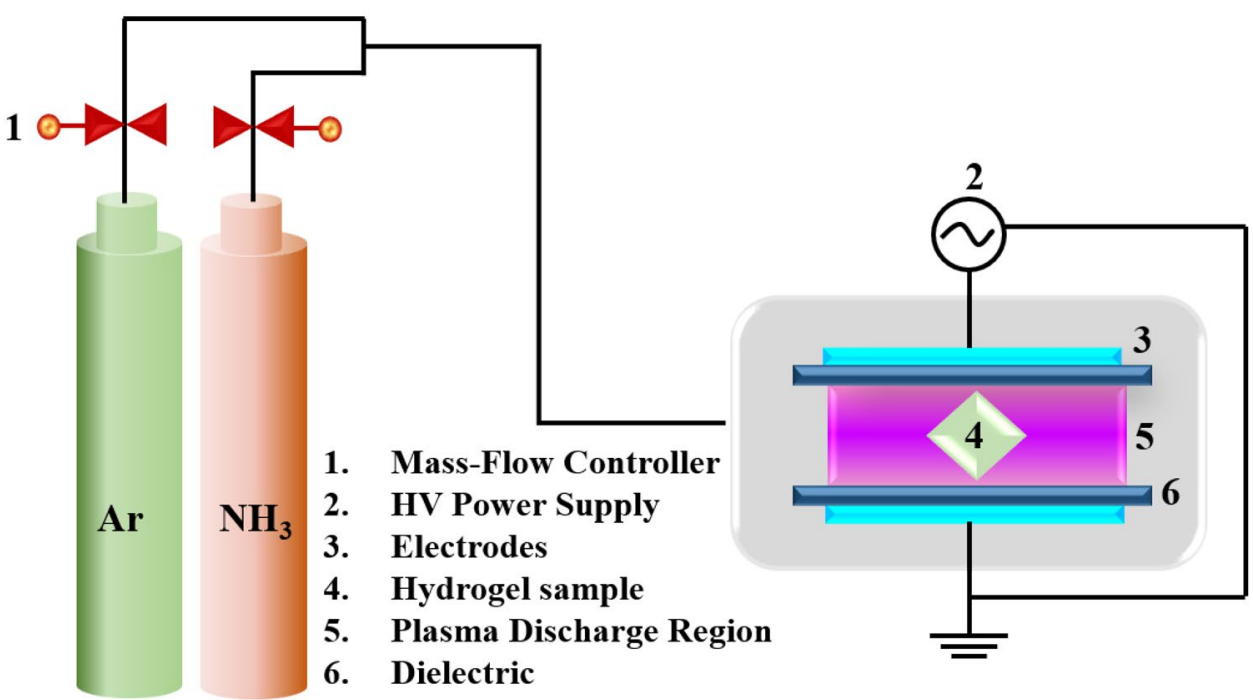

Surface treatment of the PVA/CMC hydrogels was performed in atmospheric pressure at the optimized working condition of $15 \mathrm{kV}$ voltage and $3.6 \mathrm{~W}$ plasma power for 60 s. The untreated hydrogel has been labelled as PCMC@ UT while the plasma-modified samples have been designated as PCMC@Ar, PCMC@NH 3 and PCMC@Ar $+\mathrm{NH}_{3}$ respectively in accordance with the gases employed to generate the plasma.

\subsection{Characterization techniques}

\subsubsection{Contact angle (CA) and surface free energy (SFE)}

The wettability of the hydrogels has been determined from CA measurement using the sessile drop method in a Rame-Hart Tensiometer, USA. The static contact angle was measured by employing distilled water and ethylene glycol as polar and non-polar probe liquids respectively. A drop of the test liquid was positioned on the surface of the hydrogels and the images were captured immediately. Ten different measurements of each sample were taken and the results have been reported as mean \pm SD. The SFE was also estimated using Owens, Wendt, Rabel and Kaelble (OWRK) method.

In order to examine their durability; the hydrogel specimens were exposed to air for a certain time period. The durability was estimated from CA analyses as described above.

\subsubsection{FTIR}

The hydrogels were triturated with dry $\mathrm{KBr}$, compressed into pellets and the spectra collected in a Thermo Nicolet iS5 FTIR spectrophotometer in the range of $4000-400 \mathrm{~cm}^{-1}$.

\subsubsection{AFM}

Surface topography of the hydrogels was determined in a NT-MDT, Solver Pro-47 AFM. Images were captured in tapping mode at a fixed scan rate of $0.5 \mathrm{~Hz}$. The root mean squared (rms) value have been determined to estimate surface roughness.

\subsubsection{SEM}

The hydrogels were allowed to swell in phosphate buffer (PBS, pH 7) till equilibrium, then frozen at $-20^{\circ} \mathrm{C}$ for $5 \mathrm{~h}$ followed by lyophilization at $-55^{\circ} \mathrm{C}$ for $24 \mathrm{~h}$ (Biobase Freeze Dryer). The lyophilized samples were sputtered coated and their morphology was investigated on a Carl Zeiss-EVO@18 SEM.

\subsection{Smart swelling response of hydrogels}

The $\mathrm{pH}$-dependant swelling behaviour was inspected by immersing the hydrogels in solutions of desired $\mathrm{pH}$ $(2.0-12.0)$ at $37^{\circ} \mathrm{C}$. At regular time intervals; samples were taken out, gently wiped with filter paper to remove the excess surface water and weighed. The process was continued till a constant weight was obtained. The equilibrium swelling ratio was calculated according to the following formula:

Swelling $(\%)=\frac{W_{s}-W_{d}}{W_{d}} \times 100$

where $W_{s}$ and $W_{d}$ are the weights of the swollen and dried hydrogels, respectively. 


\subsection{In vitro drug release studies and kinetics}

IBF is a potent NSAID widely prescribed for its analgesic, antipyretic and anti-inflammatory properties. It is used to relieve pain and inflammation in a wide spectrum of musculoskeletal conditions including arthritis, gout, sprains and rheumatism [55]. In this study, IBF has been loaded onto the hydrogels and its release studied. The dried hydrogels were equilibrated with IBF $(25 \mathrm{mg} / 25 \mathrm{~mL}$ ) solution (methanol: water $=1: 2$ ) for $48 \mathrm{~h}$ in dark. The release from the hydrogels was studied in phosphate buffer of $\mathrm{pH}$ 7.4. The release studies were also carried out in simulated gastric (SGF, pH 1.2) and intestinal (SIF, pH 7.4) fluids prepared according to the standard procedures. $3 \mathrm{~mL}$ aliquot samples were withdrawn from $50 \mathrm{~mL}$ of the releasing medium at regular intervals and analysed spectrophotometrically (Cary UV-100, Agilent Technologies) at $276 \mathrm{~nm}$. The withdrawn samples were replenished with $3 \mathrm{~mL}$ of fresh buffer to simulate physiological conditions. The data were expressed as the mean value of three independent experiments and the standard deviations are presented as error bars.

The drug release data were fit to four basic kinetic models namely zero order, Higuchi, Ritger-Peppas and Peppas-Sahlin equations and the best fit was determined against the highest value of correlation coefficient, $R^{2}$. These equations are given by [56]:

Zero Order: $\mathrm{M}_{t} / \mathrm{M}_{\infty}=k_{0} t$

Higuchi: $\mathrm{M}_{t} / \mathrm{M}_{\infty}=k_{\mathrm{H}} t^{1 / 2}$

Ritger-Peppas: $\mathrm{M}_{t} / \mathrm{M}_{\infty}=k_{\mathrm{RP}} t^{n}$

Peppas-Sahlin: $M_{t} / M_{\infty}=k_{1} \cdot t^{m}+k_{2} \cdot t^{2 m}$

Here, $M_{t} / M_{\infty}$ is the fractional drug release at time $t ; k_{0}, k_{H}$ and $k_{R P}$ are the respective kinetic rate constants for the zero order, Higuchi and Ritger-Peppas equations respectively. $n$ is the diffusional exponent indicative of drug transport mechanism and depends on the geometry of the releasing device. The first term of Eq. (5) represents the contribution of Fickian diffusion and the second term refers to the macromolecular relaxation contribution on the overall release process. $k_{1}$ is the diffusion and $k_{2}$ is the relaxation rate constant. The coefficient $m$ is the Fickian diffusional exponent and its value is 0.5 for thin films. Using the estimated parameters $k_{1}$ and $k_{2}$ from Eq. (6), the ratio of relaxation (R) and Fickian (F) contributions was calculated using Eq. (6) given as:

$R / F=\left(k_{2} / k_{1}\right) t^{m}$

\subsection{Biodegradability by soil burial test}

The biodegradability of the hydrogels was carried out as per the reported procedure [52]. The specimens were embedded in $1 \mathrm{~kg}$ of soil (collected from Ravenshaw University at Cuttack and used for gardening purposes). Water was sprinkled at regular intervals to prevent the drying of the soil. The biodegradability was calculated by the following equation [52]:

$W=\frac{G_{1}-G_{2}}{G_{1}} \times 100$

where $G_{1}$ and $G_{2}$ are the weights of the hydrogels before and after test, respectively.

\section{Results and discussion}

\subsection{CMC synthesis and characterization}

The schematic representation of carboxymethylation of cellulose is presented in Fig. 2a. The formation of CMC has been verified from FTIR spectral analysis (Fig. 2b). The key cellulose spectral peaks constitute $\mathrm{O}-\mathrm{H}_{\text {str }}$ vibration at $3380 \mathrm{~cm}^{-1}, \mathrm{C}-\mathrm{H}_{\mathrm{str}}$ vibration around $2900 \mathrm{~cm}^{-1}$ and an absorption band at $890 \mathrm{~cm}^{-1}$ typical of $\beta$-glucan [21]. The spectrum of CMC was significantly different from that of pristine cellulose. Two characteristic peaks at $1600 \mathrm{~cm}^{-1}$ and $1425 \mathrm{~cm}^{-1}$ which are associated with $\mathrm{COO}^{-}$antisymmetric and symmetric stretching respectively was observed suggesting the presence of carboxymethyl groups $[52,57]$. Thus, the FTIR analyses affirmed the successful carboxymethylation of cellulose.

\subsection{Characterization of PCMC hydrogels}

The plausible scheme of mechanism of hydrogel formation between CMC and PVA using TEOS as crosslinker is shown in Fig. 3.

\subsection{Surface topography analyses}

Etching processes are inevitable owing to the bombardment of high-energetic plasma particles on the hydrogel surfaces. The topographies of the pristine PCMC hydrogel and the plasma-modified hydrogels have been inspected by AFM and depicted in Fig. 4. Quite visibly, drastic topographical transformation on the hydrogels post-plasma modification was visualized. While PCMC@UT appeared smoother and even; the plasma-modified hydrogels revealed to be pretty much rough, uneven and coarse.

The etching incurred upon the hydrogels post-plasma treatment have been quantified in terms of root mean squared (rms) values. Higher the rms value, more rugged is the surface. The rms values were estimated to be $4.22 \pm 0.85,13.79 \pm 1.23,18.07 \pm 1.57$ and $24.49 \pm 2.33 \mathrm{~nm}$ 
Fig. 2 a Schematic representation of carboxymethylation of cellulose and $\mathbf{b}$ FTIR spectra of cellulose and CMC a

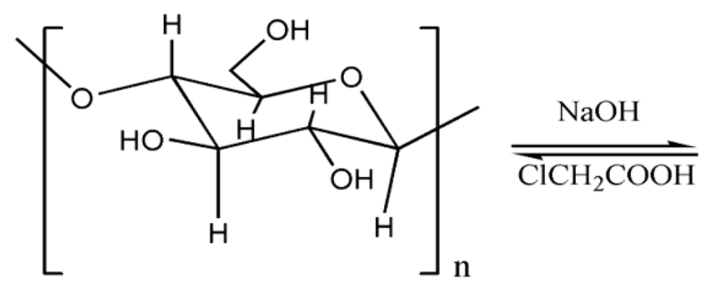

Cellulose

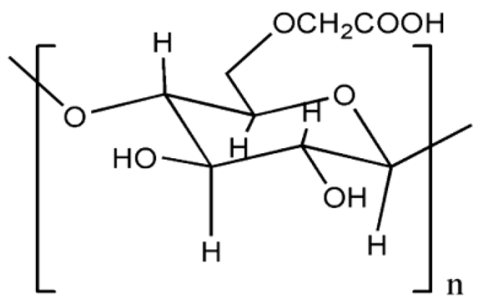

Carboxymethyl Cellulose

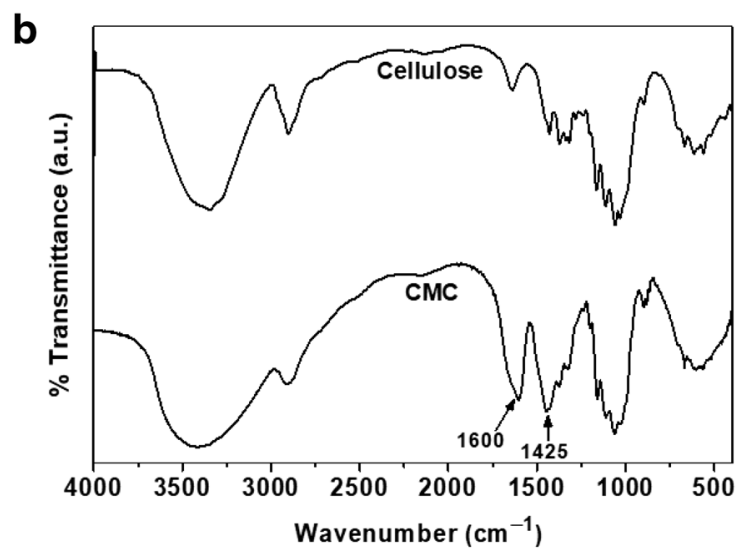

Fig. 3 Proposed schematic illustration of PVA/CMC hydrogel formation using TEOS as crosslinker

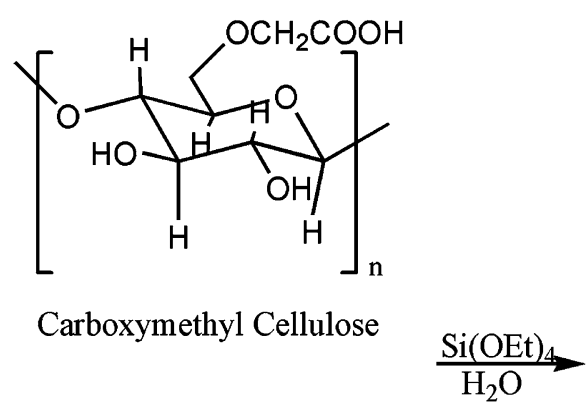<smiles>CC(C)(C)CC(O)CC(O)CC(O)C(C)(C)C</smiles>

PVA

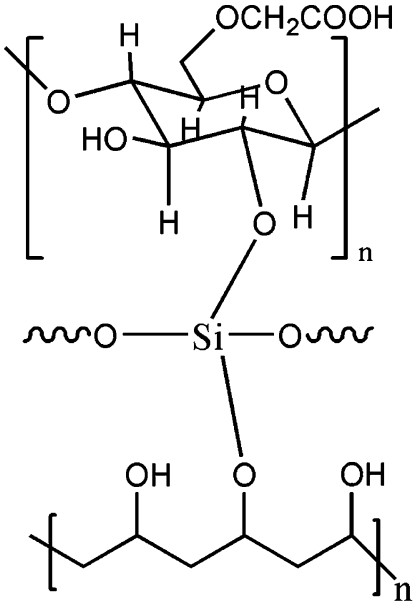

Carboxymethyl Cellulose/PVA Hydrogel respectively for PCMC@UT, PCMC@Ar, PCMC@NH 3 and $\mathrm{PCMC} @ \mathrm{Ar}+\mathrm{NH}_{3}$ hydrogels respectively. The higher degree of surface roughness of PCMC@Ar $+\mathrm{NH}_{3}$ could be accounted for the coupled effects of the $\mathrm{Ar}$ and $\mathrm{NH}_{3}$ plasmas impinging on hydrogel surface [58]. The AFM analyses were clearly suggestive of the surface nanotexturing of the hydrogels while the bulk attributes remained undeterred.

\subsection{Surface wettability analyses}

The wettability of any polymer surface can be described by the intermolecular interaction with the liquid phase that characterizes the degree of wetting of a solid surface by a liquid droplet [59]. The chemical composition and surface topography are crucial in deciphering the wettability of a polymeric surface. Surface wettability directly influences cell-biomaterial interaction in terms of adhesion, proliferation, viability and differentiation; thereby ultimately affecting the biocompatibility [11]. The CA of the hydrogels was estimated using water and ethylene glycol as probe liquids and the corresponding surface energies have been depicted in Fig. $5 a$, b respectively.

As evident from Fig. $5 \mathrm{a}$, the water CA of PCMC@UT was observed to be $67.40^{\circ} \pm 1.42^{\circ}$. However, the water 

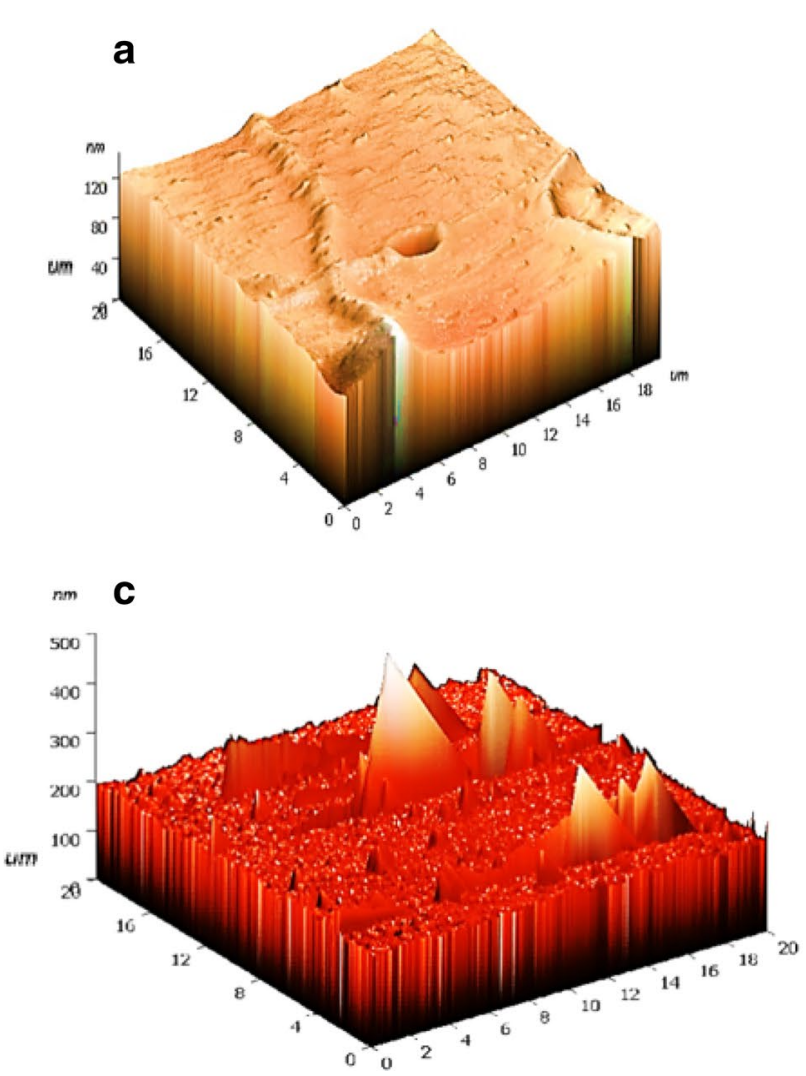
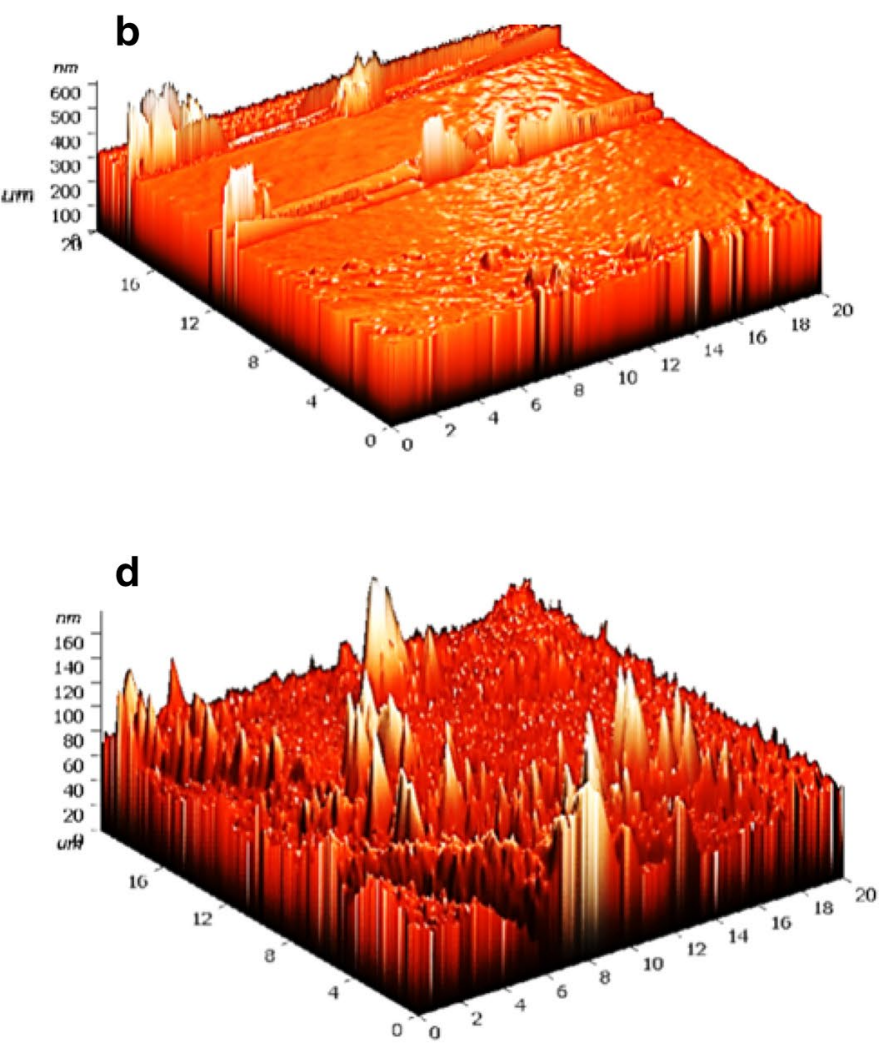

Fig. 4 3D AFM images of a PCMC@UT, b PCMC@Ar, c PCMC@NH and $\mathbf{d}$ PCMC @Ar $+\mathrm{NH}_{3}$ hydrogels

CA values decreased to $53.65^{\circ} \pm 0.70^{\circ}, 38.65^{\circ} \pm 0.83^{\circ}$ and $25.93^{\circ} \pm 0.45^{\circ}$ for PCMC@Ar, PCMC@NH 3 , PCMC@Ar $+\mathrm{NH}_{3}$ hydrogels. This lowering in $C A$ values could be particularly ascribed to the addition of new polar functional groups on the hydrogel surfaces post-plasma modification $\left(\gamma^{p}\right.$ in Fig. 5b). Generally, $\mathrm{NH}_{3}$-plasma is known to introduce amine or $-\mathrm{CONH}_{2}$ or $\mathrm{N}-\mathrm{C}=\mathrm{O}$ functionalities which are polar in nature $[58,60]$. Typically, following an Ar-plasma treatment, free radicals are generated at the hydrogel surface. These free radicals react with the oxygen from the atmosphere that eventually lead to incorporation of hydrophilic $\mathrm{C}-\mathrm{O}$ groups on the surface $[10,58,60]$. Conversely, enhanced surface hydrophilicity of PCMC@Ar+ $\mathrm{NH}_{3}$ could be explained by taking into account the coupled effects of both $\mathrm{Ar}$ and $\mathrm{NH}_{3}$ plasmas impinging on its surface. The surface hydrophilicity of the hydrogels was found to increase in the order of PCMC@UT <PCMC@Ar $<$ PCMC@ $\mathrm{NH}_{3}<\mathrm{PCMC} @ \mathrm{Ar}+\mathrm{NH}_{3}$.

Surface free energy (SFE) is an important criterion that has often been strongly correlated with the cell-biomaterial interfacial interactions. Higher the SFE; stronger is the adhesion between the two surfaces. It was witnessed that PCMC@UT presented a lower SFE value of $37.12 \pm 1.35 \mathrm{~mJ} /$ $\mathrm{m}^{2}$ whereas the energies increased to $46.20 \pm 0.64$, $62.86 \pm 1.21$ and $74.93 \pm 0.53 \mathrm{~mJ} / \mathrm{m}^{2}$ for PCMC@Ar, PCMC@
$\mathrm{NH}_{3}$ and PCMC@Ar $+\mathrm{NH}_{3}$ respectively. The PCMC@Ar $+\mathrm{NH}_{3}$ was found to be the optimum of the lot with lowest $C A$ and highest SFE characteristics.

\subsection{Hydrophobic recovery: ageing effect of hydrogels}

The durability of the pristine and plasma-modified hydrogels has been determined from the CA measurements by exposing them to air. When the plasma-treated samples are exposed to ambient environment; the newly added polar functionalities on the hydrogel films post-plasma treatment are gradually lost to the atmosphere. This phenomenon is generally referred to as hydrophobic recovery or ageing [61]. Figure 6 displays the progression in water CA values of the hydrogels with an ageing up to 10 days.

As evident from Fig. 6, the water CA of the plasmatreated samples showed a slight upward trend after 10 days of storage. This observation could be rationalized by considering the rearrangement of the hydrophilic polar groups incorporated onto the hydrogel surface during plasma treatment and the subsequent reorientation of a part of these hydrophilic groups towards the bulk thereby reducing the acquired hydrophilic nature of the treated surface [61]. Subsequent to 10 days of exposure to air; 

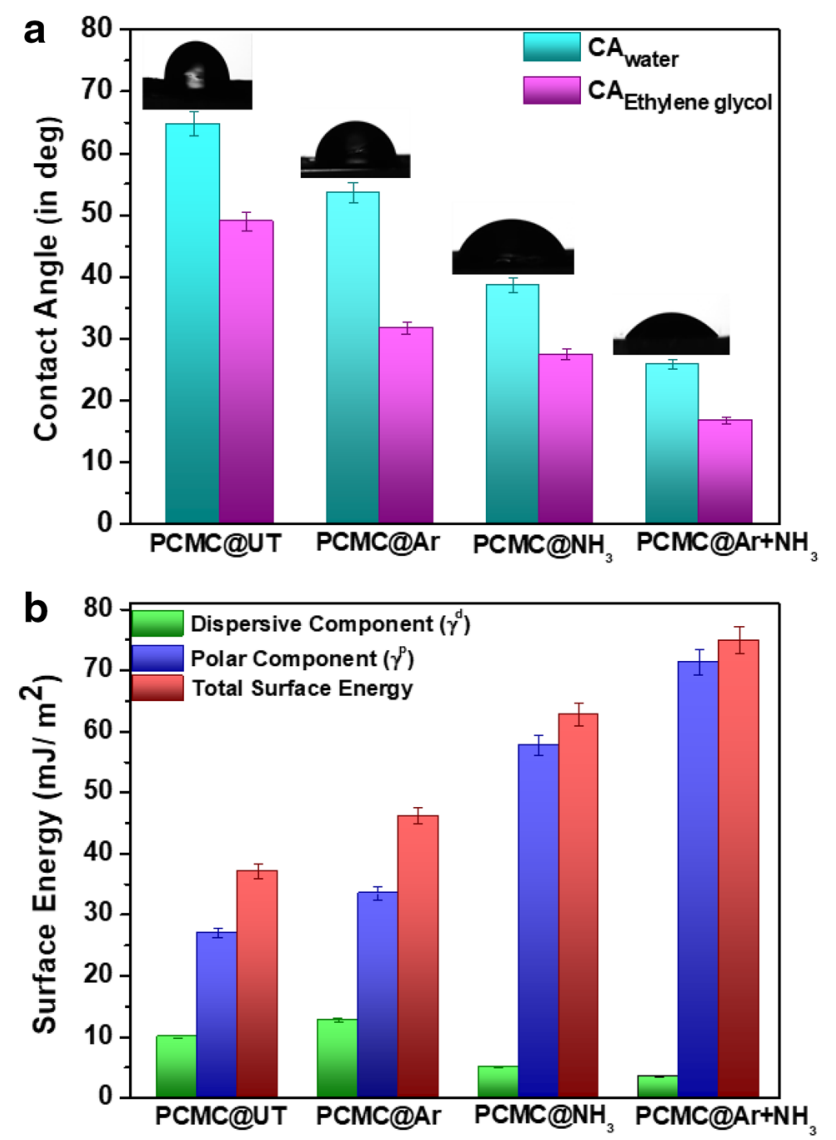

Fig. 5 a Contact angle and b surface energy of PCMC hydrogels

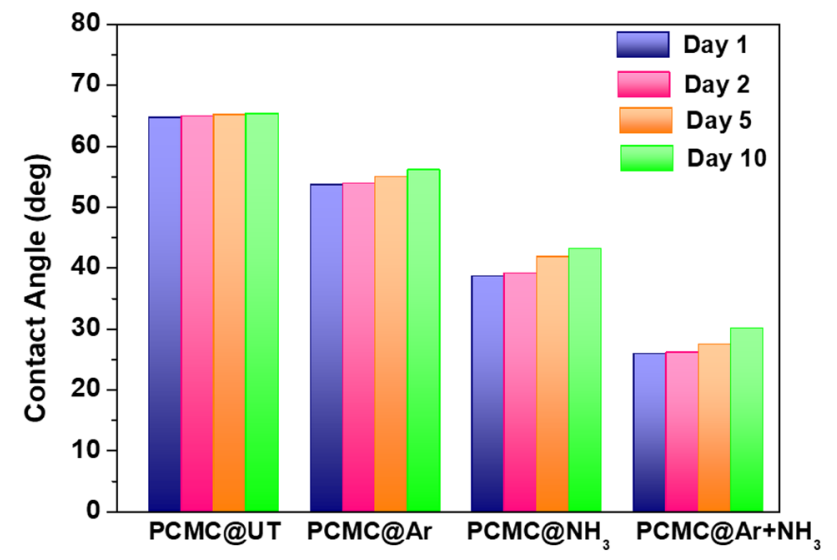

Fig. 6 Durability of the hydrogels exposed to air for 10 days

trivial alterations were witnessed in the water $C A$ values of the hydrogels. The PCMC@Ar $+\mathrm{NH}_{3}$ demonstrated the lowest $C A$ value in comparison to others even after a prolonged exposure period. Thus, the ageing studies clearly established the stability of the hydrogels post-plasma modification. Consequently, DBD plasma treatment can be considered as an effective tool for surface hydrophilic modification of PVA/CMC hydrogels.

\subsection{FTIR spectral analyses}

The FTIR spectral elucidations signify the interaction of polymers in a hydrogel and are illustrated in Fig. 7. PVA exhibits key absorption bands at $3400 \mathrm{~cm}^{-1}\left(\mathrm{O}-\mathrm{H}_{\mathrm{str}}\right)$, $2930 \mathrm{~cm}^{-1}\left(\mathrm{C}-\mathrm{H}_{\mathrm{str}}\right.$ from $-\mathrm{CH}_{2}$ groups $)$ and $1720 \mathrm{~cm}^{-1}$ $\left(C=\mathrm{O}_{\text {str }}\right)[51,52]$. The peak at $1140 \mathrm{~cm}^{-1}$ is attributed to crystalline $C=O$ stretching due to the semi-crystalline nature of PVA. In the spectra of the hydrogels, the key peaks corresponding to both PVA and CMC were present. However, the crystalline $\mathrm{C}=\mathrm{O}$ peak of PVA has disappeared altogether indicating the loss in the crystallinity due to interpolymer interaction. Additionally, a broad band was observed around $1080 \mathrm{~cm}^{-1}$ in the spectrum of all the hydrogels due to the presence of siloxane bond ( $\mathrm{Si}-\mathrm{O}-$ ) resulting from the crosslinker TEOS [53]. The FTIR spectral
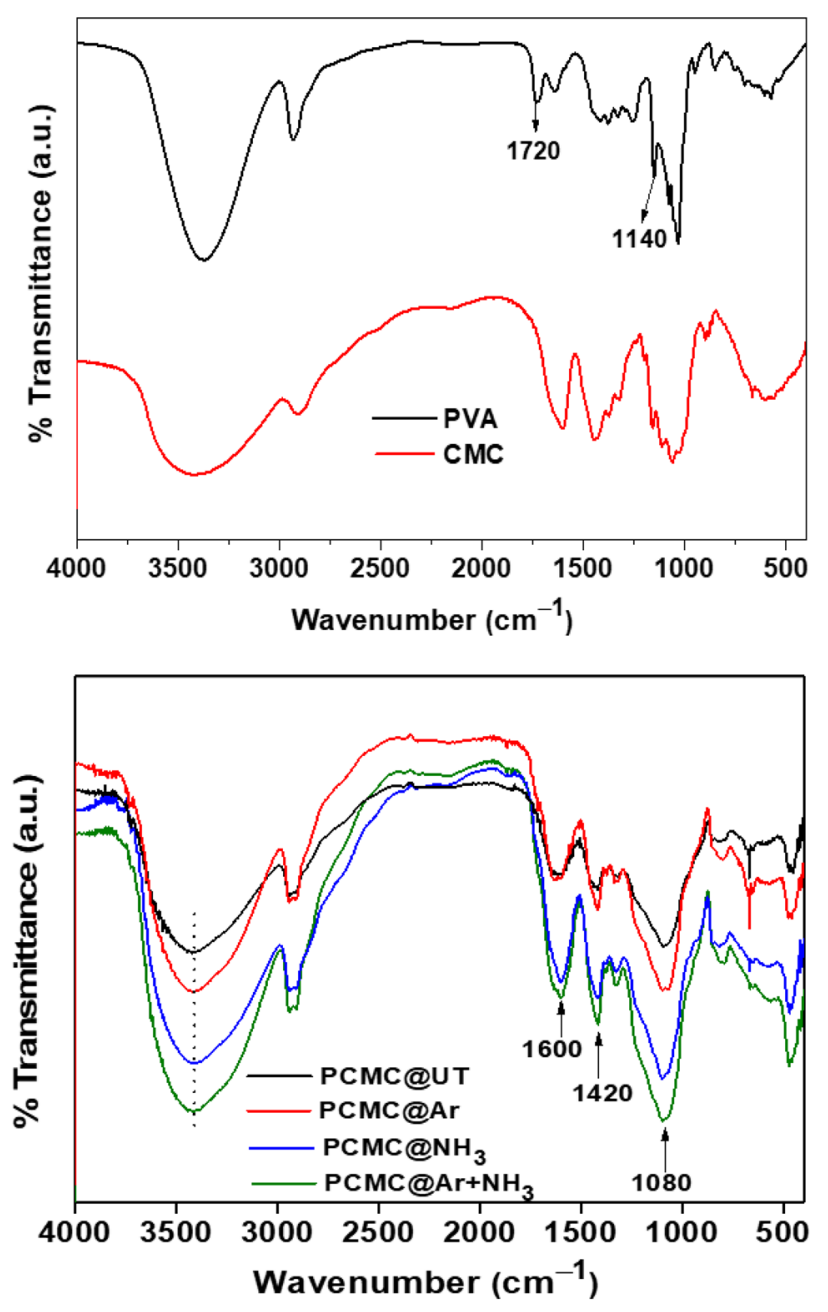

Fig. 7 FTIR spectra of PVA, CMC and PCMC hydrogels 
features of the hydrogels were more or less similar; however, the plasma-modified hydrogels displayed more significant hydroxyl absorption bands that was suggestive of their hydrophilic nature acquired post-plasma modification. Among all, the PCMC@Ar $+\mathrm{NH}_{3}$ exhibited higher $\mathrm{O}-\mathrm{H}_{\text {str }}$ which implied an increase in the hydrophilic moieties in the hydrogel.

\subsection{Smart swelling responsivity}

$\mathrm{pH}$ is a crucial parameter to be assessed for biomaterials designed for drug delivery purposes. In this study, the swelling response of the hydrogels was investigated at different $\mathrm{pHs}$. The influence of $\mathrm{pH}$ on the swelling of the hydrogels is shown in Fig. 8.

The hydrogels exhibited $\mathrm{pH}$-sensitive swelling with maximum swelling at neutral $\mathrm{pH}$ and lower swelling at acidic and basic $\mathrm{pH}$. The $\mathrm{pH}$-responsivity of the hydrogels could be ascribed to the presence of CMC which is anionic in nature and endowed with pendant carboxylic acid groups [25]. In acidic pH, most of the carboxylate anions are protonated. Thus, hydrogen-bonding interaction among carboxylic acid groups was generated. $\mathrm{H}$-bonding, being a physical crosslinker, tends to shrink the matrix thereby resulting in a decreased swelling [62]. Upon increasing the $\mathrm{pH}$ to 7; few carboxylic groups in the CMC network get deprotonated and hence, electrostatic repulsion between carboxylate anions increases and higher swelling was observed. At basic $\mathrm{pH}$, the deionization of carboxylate groups in CMC causes a shrinkage in the hydrogel matrix and swellability is reduced $[25,62]$. The swellability was found to be of the order PCMC@ $\mathrm{UT}<\mathrm{PCMC} @ \mathrm{Ar}<\mathrm{PCMC} @ \mathrm{NH}_{3}<\mathrm{PCMC} @ \mathrm{Ar}+\mathrm{NH}_{3}$. The higher swelling capacity of PCMC@Ar $+\mathrm{NH}_{3}$ could be explained

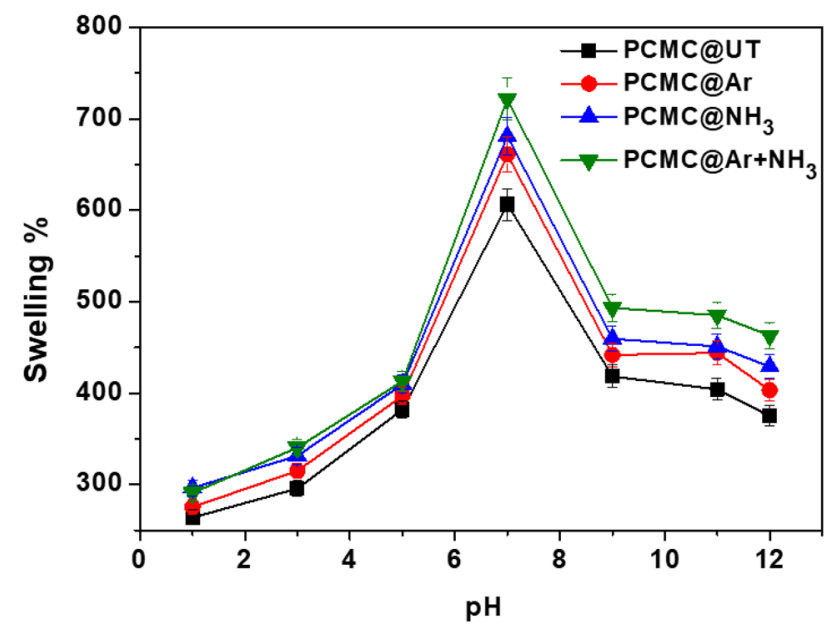

Fig. 8 Smart swelling response of PCMC hydrogels at $37^{\circ} \mathrm{C}$ by considering its improved surface hydrophilicity ensuing from DBD plasma treatment.

\subsection{Morphological analyses}

The equilibrium swollen hydrogels (in $\mathrm{pH}$ 7) were lyophilized and their morphology has been visualized by SEM (Fig. 9). The micrograph of PCMC@ UT revealed a fairly firm surface structure with the distribution of some bulges (Fig. 9a, a'). However, following DBD plasma treatment; the hydrogels exhibited a relatively regular surface. A continuous and evenly distributed 3D macroporous network structure was evident for the plasma-modified hydrogels (Figs. 9b, b', c, c', d, d'). This morphological observation could be justified by considering the surface alterations attained upon plasma-treatment that provided a new corridor for the water molecules to enter into the hydrogel matrix, thereby enhancing the porosity. Taken together with the deductions from CA, FTIR and swelling experiments; it could be inferred that plasma treatment promoted more junctions and pores in the hydrogels. Hydrogels possessing such porous morphology could be utilized as scaffolds in tissue engineering applications or as wound healing agents.

\subsection{IBF release and kinetics}

\subsubsection{In vitro IBF release studies}

To evaluate the potential of PCMC hydrogels as drug delivery systems, the release of IBF-loaded hydrogels was assessed. The drug release profiles of the hydrogels have been presented in Fig. 10.

As evident from Fig. 10a, the rates of IBF release differed for the pristine PCMC and plasma-modified PCMC hydrogels. For both the composites; more than $90 \%$ of the drug has been released after $12 \mathrm{~h}$. However, IBF release was achieved faster from PCMC@Ar $+\mathrm{NH}_{3}$ in comparison to PCMC@UT. This difference in the release profiles could be accredited to their swelling behaviour. Since PCMC@ $\mathrm{Ar}+\mathrm{NH}_{3}$ matrix has higher swellability features among others, drug release is achieved sooner.

In order to further imitate the conditions of the gastrointestinal tract; IBF release from the PCMC@Ar+ $\mathrm{NH}_{3}$ was studied in SGF and SIF. The hydrogels were immersed in SGF for $2 \mathrm{~h}$ and then transferred to SIF and the release was monitored. Figure $10 \mathrm{~b}$ depicts the release profile of IBF from PCMC@Ar + $\mathrm{NH}_{3}$ in SGF and SIF environments. Less than $20 \%$ of IBF was released during the initial $2 \mathrm{~h}$ in SGF. However, when it was transferred to SIF; the rate of IBF release increased significantly. This release profile of IBF fulfils the requirements of US Pharmacopeia for oral 

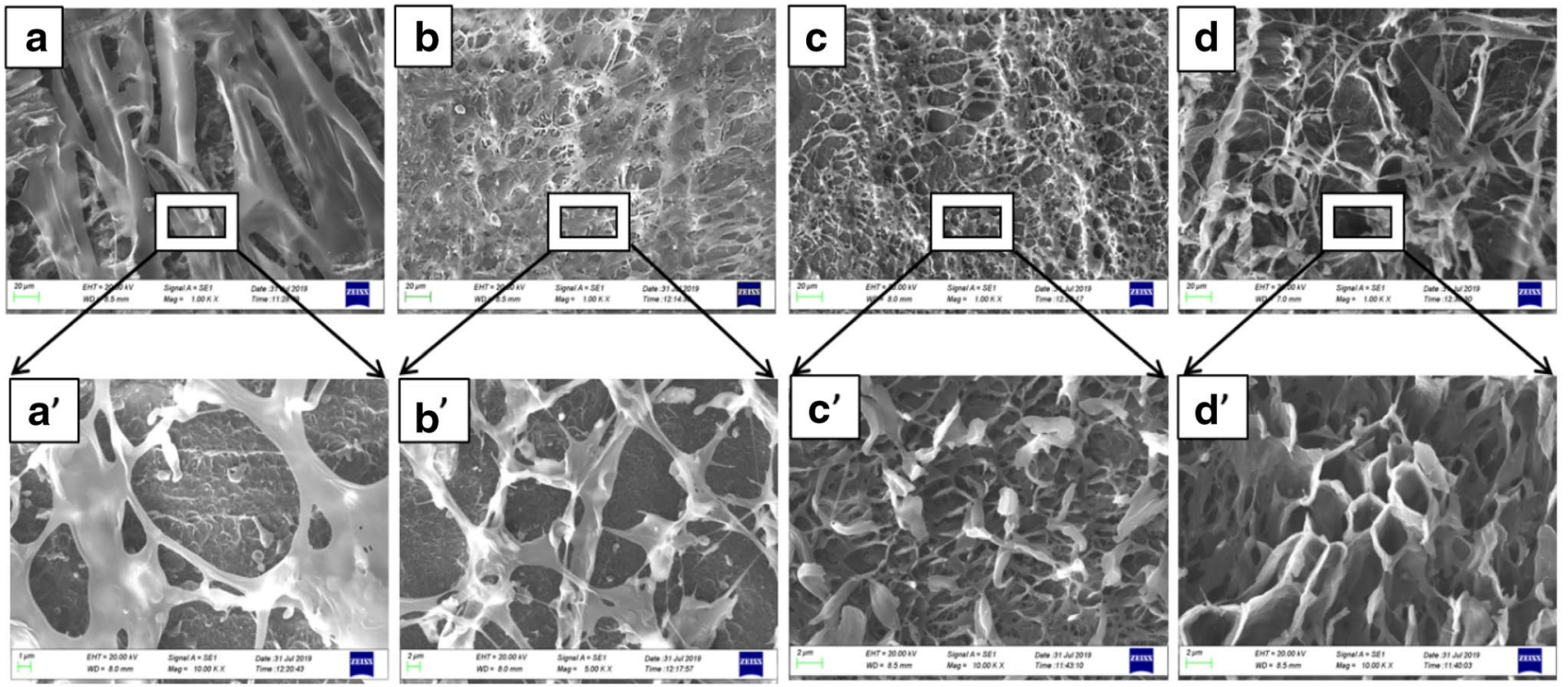

Fig. 9 SEM images of PCMC hydrogels; a PCMC@UT (a $\left.\times 1000 ; \mathbf{a}^{\prime} \times 10,000\right)$, PCMC@Ar $\left(\mathbf{b} \times 1000 ; \mathbf{b}^{\prime} \times 5000\right), \mathrm{PCMC} @ N \mathrm{H}_{3}\left(\mathbf{c} \times 1000 ; \mathbf{c}^{\prime} \times 10,000\right)$ and PCMC@Ar+ $\mathrm{NH}_{3}\left(\mathbf{d} \times 1000 ; \mathbf{d}^{\prime} \times 10,000\right)$
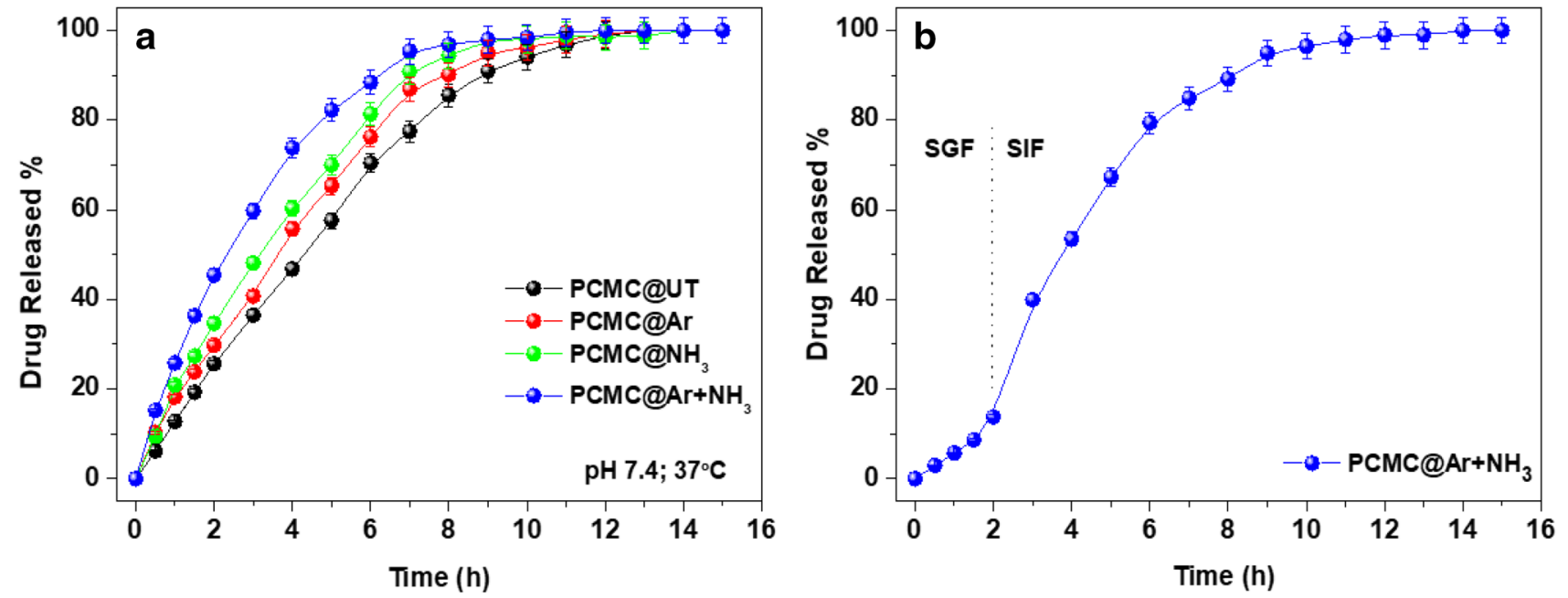

Fig. 10 IBF release profiles of PCMC hydrogels in a $\mathrm{pH} 7.4$, and $\mathbf{b}$ SGF, SIF at $37^{\circ} \mathrm{C}$

drug delivery to the lower part of the gut targeting the colon [53].

\subsubsection{IBF release kinetics}

Table 1 summarizes the kinetic parameters for IBF release data which provides an approximate idea about the drug transport mechanism from the hydrogels.

For a thin film, when $n=0.5$, the drug release mechanism is Fickian diffusion. When $n=1$, Case II transport occurs leading to zero-order kinetics. When $n$ lies between 0.5 and 1 , anomalous transport is observed. The values of $n$ lie between 0.75 and 0.91 , indicating the anomalous nature of drug release, where both diffusion and relaxation processes contribute. However, to exactly determine the contribution of these two processes, the ratio of the polymer relaxation over Fickian contributions (R/F) was calculated using the values of $k_{1}$ and $k_{2}$ and plotted against the fraction of IBF released (Fig. 11).

The predominant influence of macromolecular chain relaxation on the drug release was observed for PCMC@UT. However, ensuing plasma-modification, the drug release mechanism was mostly diffusion-controlled. The lowest R/F values of PCMC@Ar $+\mathrm{NH}_{3}$ were suggestive of the 
Table 1 Kinetic and fitting parameters for drug release data fit to various equations

\begin{tabular}{|c|c|c|c|c|c|c|c|c|c|c|}
\hline \multirow[t]{3}{*}{ Hydrogels } & \multicolumn{10}{|c|}{ Models } \\
\hline & \multicolumn{2}{|c|}{ Higuchi } & \multicolumn{3}{|c|}{ Ritger-Peppas } & \multicolumn{3}{|c|}{ Peppas-Sahlin } & \multicolumn{2}{|c|}{ Zero-order } \\
\hline & $\mathrm{k}_{\mathrm{H}}$ & $\mathrm{R}^{2}$ & $\mathrm{n}$ & $\mathrm{k}_{\mathrm{RP}}$ & $\mathrm{R}^{2}$ & $\mathrm{k}_{1}$ & $\mathrm{k}_{2}$ & $\mathrm{R}^{2}$ & $\mathrm{k}_{0}$ & $\mathrm{R}^{2}$ \\
\hline @UT & 0.215 & 0.839 & 0.91 & 0.132 & 0.999 & 0.030 & 0.102 & 0.998 & 0.118 & 0.994 \\
\hline$@ A r$ & 0.232 & 0.866 & 0.83 & 0.171 & 0.993 & 0.072 & 0.100 & 0.995 & 0.142 & 0.970 \\
\hline$@ \mathrm{NH}_{3}$ & 0.261 & 0.878 & 0.81 & 0.196 & 0.997 & 0.089 & 0.107 & 0.995 & 0.160 & 0.965 \\
\hline$@ \mathrm{Ar}+\mathrm{NH}_{3}$ & 0.311 & 0.905 & 0.75 & 0.264 & 0.998 & 0.145 & 0.118 & 0.996 & 0.217 & 0.928 \\
\hline
\end{tabular}

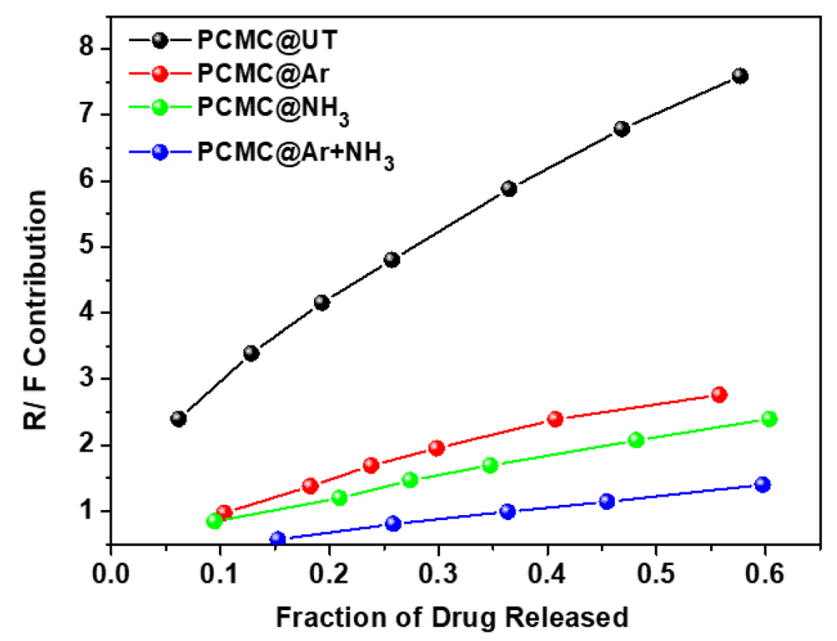

Fig. 11 Plot of R/F versus fraction of drug released from hydrogels

prevalence of diffusion process over the relaxation process that drive the drug delivery phenomenon.

\subsection{Biodegradability}

Biodegradability features of the hydrogels were assessed by the soil burial method. Microorganisms and fungi present in the soil are mainly responsible for degradation of these hydrogels. The degradation profiles of the hydrogels are shown in Fig. 12 which revealed almost 50\% degradation in a span of 30 days. These results signified the hydrogels to be biodegradable and eco-friendly in nature.

\section{Conclusion}

PVA/CMC hydrogels have been fabricated using a green crosslinker TEOS. To render the hydrogels better bioresponsivity; atmospheric DBD plasma-assisted surface modification have been performed using $\mathrm{Ar}, \mathrm{NH}_{3}$ and a mixture of the two gases. Enhanced surface wettability and free energy ensuing from the plasma treatment

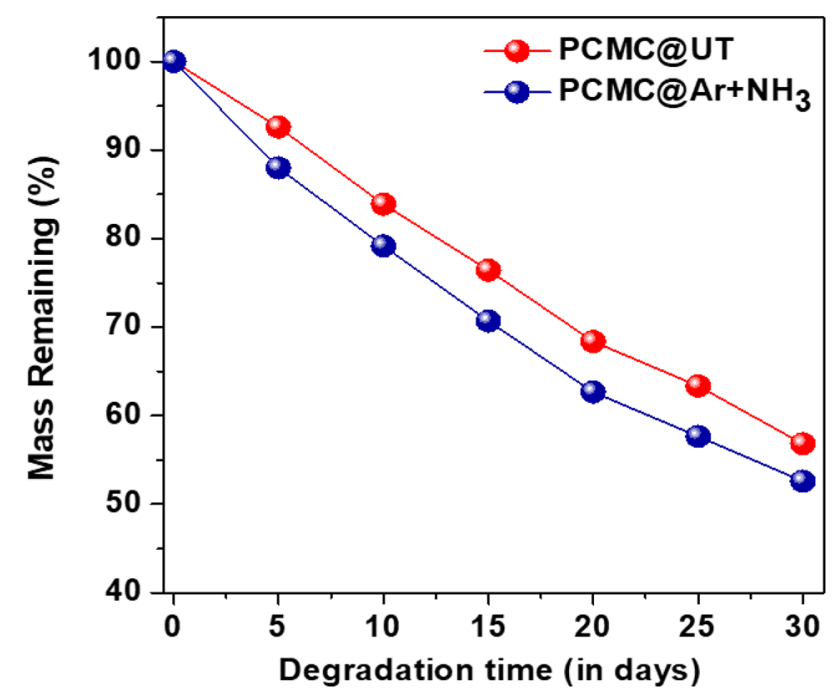

Fig. 12 Degradation profiles of PCMC@UT and PCMC@Ar $+\mathrm{NH}_{3}$ upon burying in soil for 30 days

were witnessed from CA and SFE studies. AFM analyses revealed that plasma treatment induced topographical changes at the nano level without any adverse effect on the bulk physical structure. The PCMC@Ar $+\mathrm{NH}_{3}$ exhibited higher degree of roughness likely attributed to the coupled effects of the reactive $\mathrm{Ar}$ and $\mathrm{NH}_{3}$ plasmas impinging on its surface. The hydrogels exhibited $\mathrm{pH}$ responsive swelling with maximum swelling at neutral $\mathrm{pH}$. IBF release from the hydrogels in SGF and SIF environments confirmed their potential towards oral drug delivery to the colon. The preliminary drug release kinetics revealed that drug release from plasma-modified hydrogels was predominantly diffusion-controlled. The hydrogels exhibited good biodegradability and are truly potent for drug delivery applications.

\section{Compliance with ethical standards}

Conflict of interest The authors declare that they have no conflict of interests. 


\section{References}

1. Hoare TR, Kohane DS (2008) Hydrogels in drug delivery: progress and challenges. Polymer 49:1993-2007

2. Calo E, Khutoryanskiy VV (2015) Biomedical applications of hydrogels: a review of patents and commercial products. Eur Polym J 65:252-267

3. Li J, Mooney DJ (2016) Designing hydrogels for controlled drug delivery. Nat Rev Mater 1:16071

4. Eslahi N, Abdorahim M, Simchi A (2016) Smart polymeric hydrogels for cartilage tissue engineering: a review on the chemistry and biological functions. Biomacromol 17:3441-3463

5. Kondiah PJ, Choonara YE, Kondiah PPD, Marimuthu T, Kumar P, Toit LCD, Pillay V (2016) A review of injectable polymeric hydrogel systems for application in bone tissue engineering. Molecules 21:1580

6. Saunders L, Ma PX (2019) Self-healing supramolecular hydrogels for tissue engineering applications. Macromol Biosci 19:1800313

7. Borges AMG, Benetoli LO, Licinio MA, Zoldan VC, Santos-Silva MC, Assreuy J, Pasa AA, Debacher NA, Soldi V (2013) Polymer films with surfaces unmodified and modified by non-thermal plasma as new substrates for cell adhesion. Mater Sci Eng, C 33:1315-1324

8. Bazaka K, Jacob MV, Crawford RJ, Ivanova EP (2011) Plasmaassisted surface modification of organic biopolymers to prevent bacterial attachment. Acta Biomater 7:2015-2028

9. Slepicka P, Kasalkova NS, Siegel J, Kolska Z, Bacakova L, Svorcik V (2015) Nano-structured and functionalized surfaces for cytocompatibility improvement and bactericidal action. Biotechnol Adv 33:1120-1129

10. Ramkumar MC, Pandiyaraj KN, Arunkumar A, Padmanabhan PVA, Udaykumar S, Gopinath P, Bendavid A, Cools P, De Geyter N, Morent R, Deshmukh RR (2018) Evaluation of mechanism of cold atmospheric pressure plasma assisted polymerization of acrylic acid on low density polyethylene (LDPE) film surfaces: influence of various gaseous plasma pretreatment. Appl Surf Sci 439:991-998

11. Ojah N, Saikia D, Gogoi D, Baishya P, Ahmed GA, Ramteke A, Choudhury AJ (2019) Surface modification of core-shell silk/ PVA nanofibers by oxygen dielectric barrier discharge plasma: studies of physico-chemical properties and drug release behaviour. Appl Surf Sci 475:219-229

12. Kusano Y, Madsen B, Berglun L, Oksmann K (2019) Modification of cellulose nanofibre surfaces by $\mathrm{He} / \mathrm{NH}_{3}$ plasma at atmospheric pressure. Cellulose 26:7185-7194

13. Cools $P$, Asadian M, Nicolaus W, Declercq H, Morent R, Geyter ND (2018) Surface treatment of PEOT/PBT (55/45) with a dielectric barrier discharge in air, helium, argon and nitrogen at medium pressure. Materials 11:391

14. Pankaj SK, Bueno-Ferrer C, O'Neill L, Tiwari BK, Bourke P, Cullen PJ (2017) Characterization of dielectric barrier discharge atmospheric air plasma treated chitosan films. J Food Process Preserv 41:e12889

15. Das P, Ojah N, Kandimalla R et al (2018) Surface modification of electrospun PVA/chitosan nanofibers by dielectric barrier discharge plasma at atmospheric pressure and studies of their mechanical properties and biocompatibility. Int J Biol Macromol 114:1026-1032

16. Theapsak S, Wattahanaphanit A, Rujiravanit R (2012) Preparation of chitosan-coated polyethylene packaging films by DBD plasma treatment. ACS Appl Mater Interfaces 4:2474-2482

17. Kabir SMF, Sikdar PP, Haque B, Bhuiyan MAR, Islam MN (2018) Cellulose-based hydrogel materials: chemistry, properties and their prospective applications. Prog Biomater 7:153-164
18. Fu L-H, Qi C, Ma M-G, Wan P (2019) Multi-functional cellulose based hydrogels for biomedical applications. J Mater Chem B 7:1541-1562

19. Chang C, Zhang L (2011) Cellulose-based hydrogels: present status and application prospects. Carbohydr Polym 84:40-53

20. Miao C, Hamad WY (2013) Cellulose reinforced polymer composites and nanocomposites: a critical review. Cellulose 20:2221-2262

21. Chang C, Lue A, Zhang L (2008) Effects of crosslinking methods on structure and properties of cellulose/PVA hydrogels. Macromol Chem Phys 209:1266-1273

22. Abdulkhani A, Marvast EH, Ashori A, Hamzeh Y, Karimi AN (2013) Preparation of cellulose/polyvinyl alcohol biocomposite films using 1-n-butyl-3-methylimidazolium chloride. Int J Biol Macromol 62:379-386

23. Dahlan NA, Pushpamalar J, Veeramachineni AK, Muniyandy $S$ (2018) Smart hydrogel of carboxymethyl cellulose grafted carboxymethyl polyvinyl alcohol studied for future materials applications. J Polym Environ 26:2061

24. Bisht SS, Pandey KK, Joshi G, Naithani S (2017) New route for carboxymethylation of cellulose: synthesis, structural analysis and properties. Cellul Chem Technol 51:609-617

25. Javanbakht S, Shaabani A (2019) Carboxymethyl cellulosebased oral delivery systems. Int J Biol Macromol 133:21-29

26. Gaihre B, Jayasuriya AC (2016) Fabrication and characterization of carboxymethyl cellulose novel microparticles for bone tissue engineering. Mater Sci Eng, C 69:733-743

27. Li D, Ye Y, Li D, Li X, Mu C (2016) Biological properties of dialdehyde carboxymethyl cellulose crosslinked gelatin-PEG composite hydrogel fibers for wound dressings. Carbohydr Polym 137:508-514

28. Rakhshaei R, Namazi H (2017) A potential bioactive wound dressing based on carboxymethyl cellulose/ZnO impregnated MCM-41 nanocomposite hydrogel. Mater Sci Eng, C 73:456-464

29. Sarkar C, Chowdhuri AR, Kumar A, Laha D, Garai S, Chakraborty J, Sahu SK (2018) One pot synthesis of carbon dots decorated carboxymethyl cellulose-hydroxyapatite nanocomposite for drug delivery, tissue engineering and $\mathrm{Fe}^{3+}$ ion sensing. Carbohydr Polym 181:710-718

30. Chen YM, Sun L, Yang SA, Shi L, Zheng WJ, Wei Z, Hu C (2017) Self-healing and photoluminescent carboxymethyl cellulosebased hydrogels. Eur Polym J 94:501-510

31. Baker MI, Walsh SP, Schwartz Z, Boyan BD (2012) A review of polyvinyl alcohol and its uses in cartilage and orthopaedic applications. J Biomed Mater Res Part B 100B:1451-1457

32. Kobayashi M, Hyu HS (2010) Development and evaluation of polyvinyl alcohol hydrogels as an artificial articular cartilage for orthopaedic implants. Materials 3:2753-2771

33. Paradossi G, Cavalieri F, Chiessi E, Spagnoli C, Cowman MK (2003) Polyvinyl alcohol as a versatile biomaterial for potential biomedical applications. J Mater Sci Mater Med 14:687-691

34. Kumar A, Han SS (2017) PVA-based hydrogels for tissue engineering: a review. Int J Polym Mater Polym Biomater 66:159-182

35. Teodorescu M, Bercea M, Morariu S (2018) Biomaterials of polyvinyl alcohol and natural polymers. Polym Rev 58:247-287

36. Kamoun EA, Chen X, Eldin MSM, Kenawy ERS (2015) Crosslinked poly(vinyl alcohol) hydrogels for wound dressing applications: a review of remarkably blended polymers. Arab J Chem 8:1-14

37. Deerenberg EB et al (2012) Polyvinyl alcohol hydrogel decreases formation of adhesions in a rat model of peritonitis. Surg Infect 13(5):321-325

38. Joorabloo A et al (2019) Fabrication of heparinized nano $\mathrm{ZnO} /$ poly(vinylalcohol)/carboxymethyl cellulose bionanocomposite hydrogels using artificial neural network for wound dressing application. J Ind Eng Chem 70:253-263 
39. Ghorpade VS, Dias RJ, Mali KK, Mulla SI (2019) Citric acid crosslinked carboxymethylcellulose-polyvinyl alcohol hydrogel films for extended release of water soluble basic drugs. J Drug Deliv Sci Technol 52:421-430

40. Xiao C, Gao Y (2008) Preparation and properties of physically crosslinked sodium carboxymethylcellulose/poly(vinyl alcohol) complex hydrogels. J Appl Polym Sci 107:1568-1572

41. Muppalla SR, Kanatt SR, Chawla SP, Sharma A (2014) Carboxymethyl cellulose-polyvinyl alcohol films with clove oil for active packaging of ground chicken meat. Food Packag Shelf-Life 2:51-58

42. Wang S, Zhang Q, Tan B, Liu L, Shi L (2011) pH-Sensitive poly(vinyl alcohol)/sodium carboxymethylcellulose hydrogel beads for drug delivery. J Macromol Sci B 50:2307-2317

43. Saadiah MA, Zhang D, Nagao Y, Muzakir SK, Samsudin AS (2019) Reducing crystallinity on thin film based CMC/PVA hybrid polymer for application as a host in polymer electrolytes. J Non-Cryst Solids 511:201-211

44. Dai H, Huang Y, Huang $H$ (2018) Eco-friendly polyvinyl alcohol/ carboxymethyl cellulose hydrogels reinforced with graphene oxide and bentonite for enhanced adsorption of methylene blue. Carbohydr Polym 185:1-11

45. El Salmawi KM (2007) Application of polyvinyl alcohol (PVA)/ carboxymethyl cellulose (CMC) hydrogel produced by conventional crosslinking or by freezing and thawing. J Macromol Sci Part A Pure Appl Chem 44:619-624

46. El Sayed AM (2014) Synthesis and controlling the optical and dielectric properties of CMC/PVA blend via $\gamma$-rays irradiation. Nucl Instrum Methods Phys Res B 321:41-48

47. Abou Taleb MF, Abd El-Mohdy HL, Abd El-Rehim HA (2009) Radiation preparation of PVA/CMC copolymers and their application in removal of dyes. J Hazard Mater 168:68-75

48. Wang LY, Wang MJ (2016) Removal of heavy metal ions by poly(vinyl alcohol) and carboxymethyl cellulose composite hydrogels prepared by a freeze-thaw method. ACS Sustain Chem Eng 4(5):2830-2837

49. El-Sayed S, Mahmoud KH, Fatah AA, Hassen A (2011) DSC, TGA and dielectric properties of carboxymethyl cellulose/polyvinyl alcohol blends. Phys B 406:4068-4076

50. Mohod AV, Gogate PR (2011) Ultrasonic degradation of polymers: effect of operating parameters and intensification using additives for carboxymethyl cellulose (CMC) and polyvinyl alcohol (PVA). Ultrason Sonochem 18:727-734

51. Kumar B, Sauraj Negi YS (2019) To investigate the effect of esterlinkage on the properties of polyvinyl alcohol/carboxymethyl cellulose based hydrogel. Mater Lett 252:308-312

52. Zhang L, Zhang G, Lu J, Liang H (2013) Preparation and characterization of carboxymethyl cellulose/polyvinyl alcohol blend film as a potential coating material. Polym Plast Technol Eng 52:163-167

53. Islam A, Yasin T (2012) Controlled delivery of drug from $\mathrm{pH}$ sensitive chitosan/poly(vinyl alcohol) blend. Carbohydr Polym 88:1055-1060

54. Hebeish AA, El-Rafie MH, Abdel-Mohdy FA, Abdel-Halim ES, Emam HE (2010) Carboxymethyl cellulose for green synthesis and stabilization of silver nanoparticles. Carbohydr Polym 82:933-941

55. Manzoori JL, Amjadi M (2003) Spectrofluorimetric study of hostguest complexation of ibuprofen with $\beta$-cyclodextrin and its analytical application. Spectrochim Acta, Part A 59:909-916

56. Serra L, Domenech J, Peppas NA (2006) Drug transport mechanisms and release kinetics from molecularly designed poly(acrylic acid-g-ethylene glycol) hydrogels. Biomaterials 27:5440-5451

57. Baiya C, Nannuan L, Tassanapukdee Y, Chailapakul O, Songsrirote K (2019) The synthesis of carboxymethyl cellulose-based hydrogel from sugarcane bagasse using microwave-assisted irradiation for selective adsorption of copper (II) ions. Environ Prog Sustain Energy 38:S157-S165

58. Surmenev RA et al (2019) Low-temperature argon and ammonia plasma treatment of poly-3-hydroxybutyrate films: surface topography and chemistry changes affect fibroblast cells in vitro. Eur Polym J 112:137-145

59. Yilgor I, Bilgin S, Isik M, Yilgor E (2012) Tunable wetting of polymer surfaces. Langmuir 28:14808-14814

60. Desmet T, Morent R, Geyter ND, Leys C, Schacht E, Dubruel P (2009) Non-thermal plasma technology as a versatile strategy for polymeric biomaterials surface modification: a review. Biomacromol 10:2351-2378

61. Dong S, Guo P, Chen Y, Chen G, Ji H, Ran Y, Li S, Chen Y (2018) Surface modification via atmospheric cold plasma (ACP): improved functional properties and characterization of zein film. Ind Crop Prod 115:124-133

62. Javanbakht S, Pooresmaeil M, Hashemi H, Namazi H (2018) Carboxymethylcellulose capsulated $\mathrm{Cu}$-based metal-organic framework-drug nanohybrid as a $\mathrm{pH}$-sensitive nanocomposite for ibuprofen oral delivery. Int J Biol Macromol 119:588-596

Publisher's Note Springer Nature remains neutral with regard to jurisdictional claims in published maps and institutional affiliations. 